Portland State University

PDXScholar

\title{
The Effects of Demand-Responsive Parking on Transit Usage and Congestion: Evidence From Sfpark
}

Nicole S. Ngo

University of Oregon

Chandra Kiran Krishnamurth

Swedish Agricultural University

Follow this and additional works at: https://pdxscholar.library.pdx.edu/trec_reports

Part of the Transportation Commons, and the Urban Studies Commons Let us know how access to this document benefits you.

\section{Recommended Citation}

Ngo, N.S. \& Krishnamurthy, C.K. Parking, transit usage, and congestion: Evidence from SFpark NITCRR-870. Portland, OR: Transportation Research and Education Center (TREC), 2017. https://doi.org/ 10.15760/trec.183

This Report is brought to you for free and open access. It has been accepted for inclusion in TREC Final Reports by an authorized administrator of PDXScholar. Please contact us if we can make this document more accessible: pdxscholar@pdx.edu. 


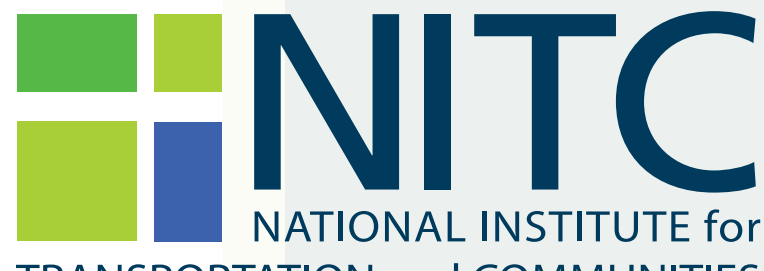

TRANSPORTATION and COMMUNITIES

FINAL REPORT

The Effects of Demand-Responsive Parking on Transit Usage and Congestion: Evidence From Sfpark

NITC-RR-870 — September 2017

NITC is a U.S. Department of Transportation

national university transportation center.

H:H TREC 



\title{
THE EFFECTS OF DEMAND-RESPONSIVE PARKING ON TRANSIT USAGE AND CONGESTION: EVIDENCE FROM SFPARK
}

\author{
Final Report \\ NITC-RR-870 \\ by \\ Nicole S. Ngo, Ph.D. \\ University of Oregon \\ Chandra Kiran Krishnamurthy, Ph.D. \\ Swedish Agricultural University
}

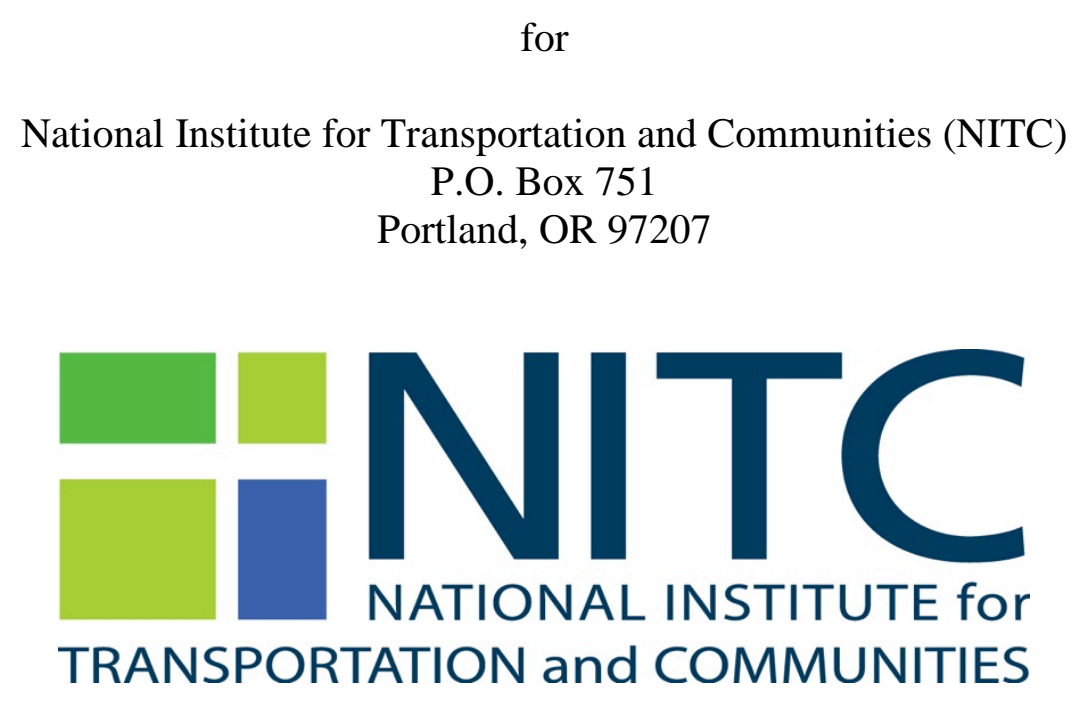

September 2017 




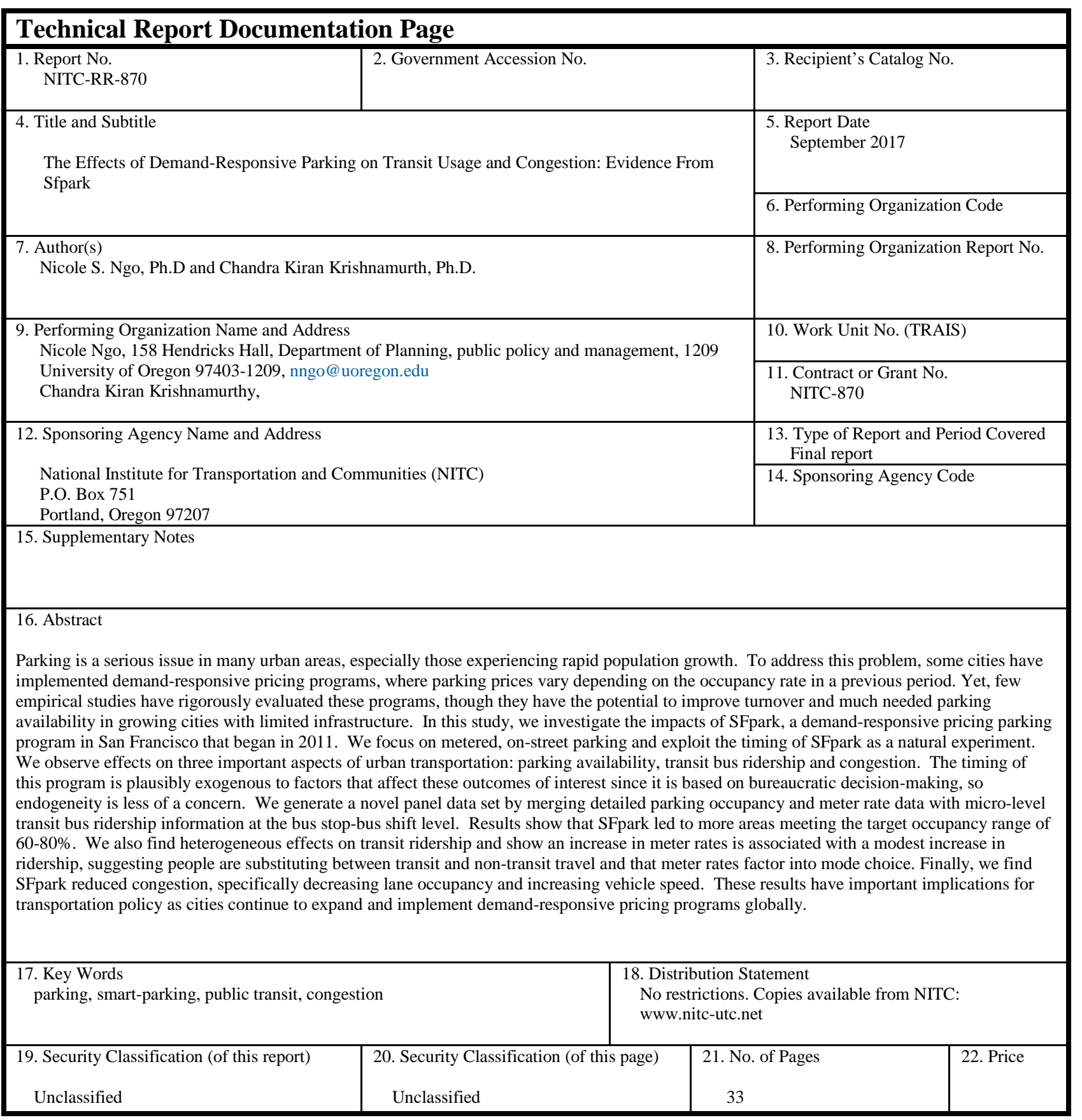





\section{ACKNOWLEDGEMENTS}

This project was funded by the National Institute for Transportation and Communities (NITC) under grant number 870 and the University of Oregon Underrepresented Minority Program grant. We also thank the Beijier Institute of Ecological Economics and student researchers, Jonathan Bennett and Tyce Herrman, who helped with this project.

\section{DISCLAIMER}

The contents of this report reflect the views of the authors, who are solely responsible for the facts and the accuracy of the material and information presented herein. This document is disseminated under the sponsorship of the U.S. Department of Transportation University Transportation Centers Program and the University of Oregon in the interest of information exchange. The U.S. Government and University of Oregon assumes no liability for the contents or use thereof. The contents do not necessarily reflect the official views of the U.S. Government and University of Oregon. This report does not constitute a standard, specification, or regulation.

\section{RECOMMENDED CITATION}

Ngo, N.S. \& Krishnamurthy, C.K. Parking, transit usage, and congestion: Evidence from SFpark. NITC-RR-870. Portland, OR: Transportation Research and Education Center (TREC), 2017. 



\section{TABLE OF CONTENTS}

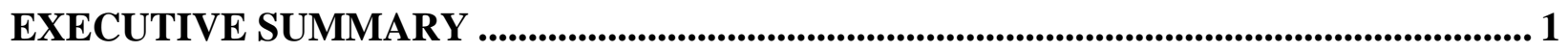

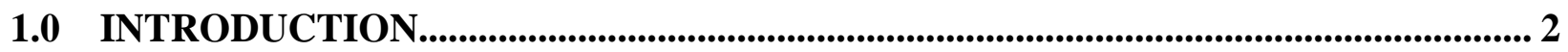

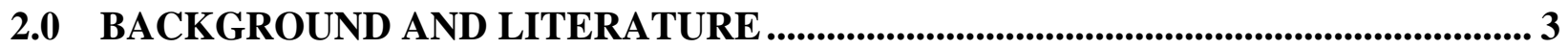

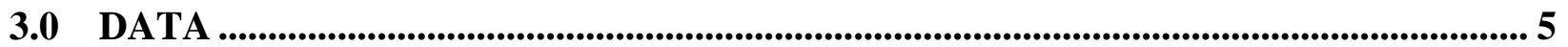

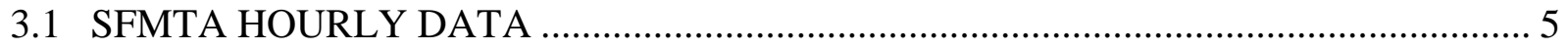

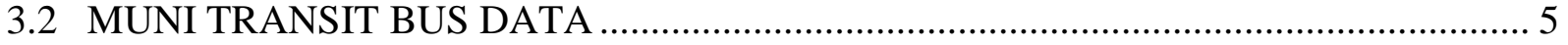

3.3 MERGING MUNI TRANSIT BUS DATA WITH SFMTA HOURLY DATA............... 6

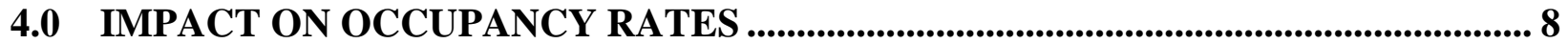

4.1 REGRESSION FRAMEWORK

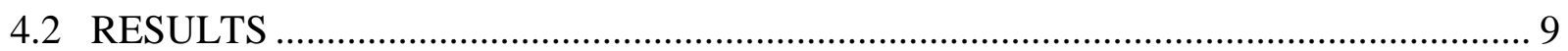

5.0 TRANSIT USAGE ............................................ ERROR! BOOKMARK NOT DEFINED.

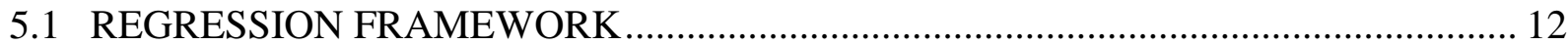

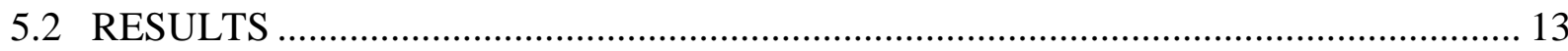

5.3 OTHER TESTS AND ROBUSTNESS CHECKS ...............................13

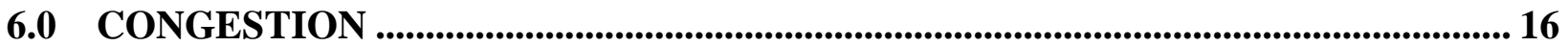

6.1 DAILY LANE OCCUPANCY, VEHICLE COUNT AND SPEED ............................. 16

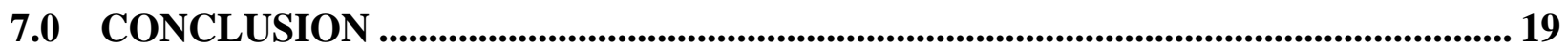

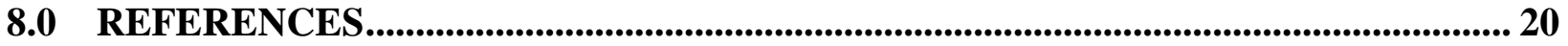

\section{APPENDICES}

APPENDIX A: MORE INFORMATION ON SFPARK DATA

\section{LIST OF TABLES}

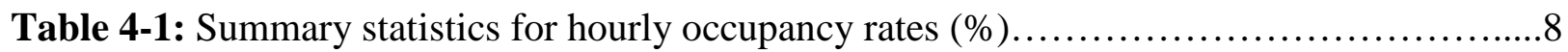

Table 4-2: Impacts of SFpark on distance from the target occupancy range of $60-80 \% \ldots \ldots \ldots . . . . .10$

Table 5-1: Impacts of SFpark on Muni bus transit ridership using equation (5-1)....................14

Table 5-2: Impacts of SFpark on Muni bus transit ridership using a different specification .....15

Table 6-1: Impacts of SFpark on different average daily measures of congestion..............18

\section{LIST OF FIGURES}

Figure 3-1. Example of parking block faces assigned by SFpark (green lines) and census blocks from the 2010 U.S. Census (black lines)............................................... Figure 4-1: Graph of average monthly parking occupancy for pilot and control blocks before and after SFpark, which started in July 2011 (represented by the vertical line)...................8 Figure 5-1: This graph shows average daily ridership (weekdays only) prior to SFpark for the months of October to December for 2009 and 2010. The dashed and solid line represent control

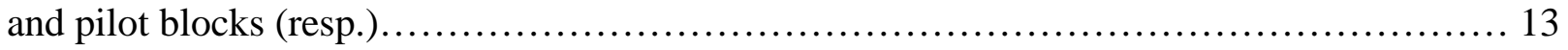





\section{EXECUTIVE SUMMARY}

Parking is a serious issue in many urban areas, especially those experiencing rapid population growth. To address this problem, some cities have implemented demand-responsive pricing programs, where parking prices vary depending on the occupancy rate in a previous period. Yet, few empirical studies have rigorously evaluated these programs, though they have the potential to improve turnover and much needed parking availability in growing cities with limited infrastructure.

One example of a rapidly growing city where excess demand for parking has become a major problem is San Francisco. In a 2015 survey by the San Francisco Municipal Transportation Agency (SFMTA), Bay area residents were asked what motivated them to drive, and the most important factors included distance between the destination and parking and parking price. Half of Bay area residents considered parking prices as being "free or cheap" as a strong motivator to drive. With continued population growth, concerns over parking will only worsen unless parking management changes. The introduction and growth of demand responsive pricing programs has the potential to resolve this issue. The goal of these programs is to use parking spaces more efficiently, encouraging turnover and increasing parking availability by differentially pricing parking based on occupancy.

In this study, we investigate the impacts of SFpark, a demand-responsive pricing parking program in San Francisco that began in 2011. We observe effects on three important aspects of urban transportation: parking availability, transit bus ridership and congestion. The timing of this program is plausibly exogenous to factors that affect these outcomes of interest since it is based on bureaucratic decision-making, so endogeneity is less of a concern.

We use data from the SFpark pilot evaluation for on-street parking, which includes hourly data on parking occupancy, metered rates and measures of daily traffic congestion. Additionally, we generate a novel panel data set using micro-level Muni bus transit data at the bus shift-stop level to observe possible effects on modal transportation choice.

Results show that SFpark achieved its primary goal of increasing parking availability, with more on-street parking meeting the target occupancy range of 60-80\%. Another component of this paper considers the impacts of blocks that used time limits prior to manage parking, but later switched to metered parking as part of SFpark. Understanding the effects on parking availability from this switch could have important implications for existing businesses concerned with reduced foot traffic. However, we find no significant effects on parking availability at blocks with newly installed meters, making their impact less clear. We also make a novel contribution to the literature by addressing the effect of SFPark on transit usage and find heterogeneous effects on ridership depending on changes in meter rates. A core component of SFpark is allowing metered rates to fluctuate after a few weeks in response to changes in occupancy. We leverage these changes in metered rates and find a positive relationship between rate changes and bus ridership, where a modest increase (decrease) in meter rates is associated with higher (lower) ridership. To our knowledge, this is the first study to rigorously assess this relationship using micro-level transit and detailed parking data. Finally, we find SFpark reduced congestion, specifically decreasing lane occupancy and increasing vehicle speed. These results have important implications for transportation policy as cities continue to expand and implement demand-responsive pricing programs globally. 


\subsection{INTRODUCTION}

Parking is a growing problem in U.S. cities due to the increasing number of drivers and the fact that cars remain parked about 95\% of the time (Marsden, 2006; Shoup, 2011). Yet, there is little empirical work on this topic within the transportation literature, even though previous studies show parking in the U.S. is grossly underpriced and inefficient, leading to increased adverse effects including cruising for parking and worsening air quality. Acknowledging that much of this is driven by mis- and underpriced parking, cities are beginning to implement or consider demand-responsive pricing programs as one possible solution. The primary goal of these programs is to use parking spaces more efficiently by encouraging turnover and increasing parking availability by differentially pricing parking based on occupancy. For example, the more popular parking spots or times would have higher meter rates compared to areas with lower occupancy, potentially generating more turnover than flat meter rates or time enforced limits. Aside from increased parking availability, there is the potential for other welfare impacts, including reduced congestion and possibly changing tradeoffs involved in modal transportation choices. These programs have recently been introduced in cities experiencing a rapid growth in population and excess demand for parking. However, few empirical studies have evaluated them rigorously to examine the degree to which, and the dimensions along which, these programs have been successful.

One example of a rapidly growing city where excess demand for parking has become a serious issue is San Francisco. According to the U.S. Census Bureau (2016), San Francisco County grew by $7.4 \%$ or approximately 60,000 people between 2010 and 2015. This type of growth could lead to increased pressures on existing infrastructures, such as parking. In a 2015 survey by the San Francisco Municipal Transportation Agency (SFMTA), Bay area residents were asked what motivated them to drive, and the most important factors included distance between the destination and parking and parking price. In fact, half of Bay area residents considered parking prices as being "free or cheap" as a strong motivator to drive. With continued growth, concerns over parking will only worsen unless parking management changes. The introduction and growth of demand responsive pricing programs has the potential to help resolve this issue.

In this study, we investigate the effects of SFpark, a demand-responsive pricing parking program in San Francisco that began in 2011. We exploit the timing of SFpark and consider it a "natural experiment," enabling us to avoid issues of endogeneity and report results from reducedform empirical analysis. More explicitly, since the commencement of, and choice of blocks in, SFpark was based on bureaucratic decision-making and logistical considerations, it is unlikely correlated to other factors that affect our outcomes of interest, minimizing potential omitted variable bias. We explore many aspects of the relationship between parking and urban transportation, in particular focusing on three that have been discussed in largely disparate literatures: parking availability, transit usage and congestion. While economists have been increasingly using empirical approaches to explore important large-scale questions related to urban transportation, such as the value of urban transit (Anderson, 2014) or the potential of urban 
transit to provide congestion relief in U.S. cities (Duranton \& Turner, 2011), the empirical literature on the relationship between parking policies and urban transportation remains small.

We use data from the SFpark pilot evaluation for on-street parking, which includes hourly data on parking occupancy, metered rates and measures of daily traffic congestion. Given the dearth of parking data, different aspects of the data from SFpark have been used in more recent literature to address important questions regarding different aspects of parking policies, (e.g., Millard-Ball, Weinberger \& Hampshire, 2013; Millard-Ball, Weinberger \& Hampshire, 2014; Pierce \& Shoup, 2013a; Pierce \& Shoup, 2013b; SFMTA, 2014). We supplement the SFpark data set with a rich and extremely detailed panel data set on transit buses that includes information at the bus shift-stop level. We use these data to discern effects on modal transportation choice resulting from the implementation of SFpark.

Our findings shed light on several aspects of urban transport that relate to parking. First, our results agree with previous work on SFpark, which found that the program achieved its primary goal of increasing parking availability. Additionally, we highlight a couple other effects: SFpark appears to exert no significant effect on newly metered blocks, making the impacts of meter installations less clear, and we document a positive effect of SFpark on transit usage, indicating that mode choice is (parking) price sensitive, a result that is commonly reported in stated-preference studies. Finally, we find SFpark led to reduced congestion, though the size of this effect varies by congestion measure. These empirical results have important implications for demand-responsive pricing programs and transportation policy, especially concerning the relationship between parking and mode choice. More empirical studies are needed to further evaluate these relationships, preferably using larger micro data sets that are generalizable to other cities and populations.

\subsection{BACKGROUND AND LITERATURE}

Many global cities experiencing rapid urban growth, such as in China, have considered using demand-responsive pricing to address the growing disparities between parking demand and supply (Wang and Yuan 2013; Asian Development Bank 2011). Europe has also examined more market-oriented parking practices to increase turn over and address the excessive demand for parking (Mingardo et al. 2015; Kondranksy and Hermann 2011). In fact, a couple studies in Europe show that appropriate pricing of parking is an important feature of effective parking management (van Ommeren et al. 2011; Fadeyev 2017). There is also a growing interest in a demand-responsive off-street parking (Barter 2009). However, due to scarce parking data, few studies have empirically examined the effectiveness of these programs, in which case the data produced by SFpark offers a unique opportunity to evaluate these programs.

Prior to SFpark, San Francisco, like many other U.S. cities, set flat meter rates that were updated periodically by the San Francisco Board of Supervisors based on recommendations by SFMTA. Meter rates did not change during the time of day or year and only varied by location, where prices were highest in downtown (\$3.50 prior to SFpark) and lower in neighborhood commercial districts (\$2.00). They also used time limits as a way to encourage parking turnover. However, it is unclear if flat meter rates or time limits are an effective strategy to increase turnover since enforcing these limits is challenging. 
SFpark, which is administered by SFMTA, was approved in 2008, commenced in July 2011 (SFMTA, 2014). We use data specifically from the SFpark pilot program which included seven parking management districts: the Civic Center, Downtown, Fillmore, Fisherman's Wharf, Marina, Mission, and South Embarcadero. They together encompass 6,000 metered parking spaces or $25 \%$ of the city's total on-street parking. The main goal of SFpark was to improve parking turnover and availability through demand-responsive pricing, which could vary over time and across blocks. Other parts of the program included allowing credit cards at all meters, improving the convenience of parking. Parking rates changed according to average occupancy rates in the previous rate adjustment period. Each rate adjustment period lasts 8 weeks. The target occupancy range is $60-80 \%$ per block-face and time band. Time bands are separated into morning hours (7am to 12pm), early afternoon (12pm to 3pm), evening hours (3pm to $6 \mathrm{pm}$ ) and night hours (after $6 \mathrm{pm}$ ) in a few cases. Metering of on-street parking typically concludes at 6pm, although in certain areas it continues throughout the night. ${ }^{1}$

Parking rate changes were based upon average occupancy over the previous rate adjustment period. If average occupancy in the previous period fell within the target range, prices did not change. However, if average occupancy exceeded $80 \%$ in the previous period, then hourly parking rates increase by $\$ 0.25$ per hour. If occupancy rates fell between 30 and $60 \%$ or < $30 \%$ then parking rates decreased resp. by $\$ 0.25$ and $\$ 0.50$. Updates to parking rates are posted by the SFMTA on SFpark's website at least 7 days prior to the change. Hourly rates cannot exceed $\$ 6.00$ per hour or go below $\$ 0.25$ per hour. SFpark also allows for longer time limits at metered parking up to 4 hours instead of 1 or 2 hours. Additionally, starting January 6, 2013, SFMTA implemented metered on-street parking on Sundays between 12pm and 6pm in select areas as an experiment, whereas before parking on Sunday in most areas was free. ${ }^{2}$

SFpark conducted an evaluation of its pilot program between 2011 and 2013 (SFMTA, 2014). The evaluation also included 2 control parking management districts: Inner Richmond and Union. At these block faces, metered parking rates did not change. The pilot study found that parking met the target occupancy range at a higher rate at pilot blocks compared to control blocks. The evaluation also found improvements in congestion, specifically traffic volume and speed. While these results are informative, the study did not account for control variables, so results could possibly under- or over-estimate the effects of SFpark if there were other factors occurring simultaneously that affected occupancy rates or the outcomes of interest in these areas. Additionally, there was no rigorous assessment of impacts on other forms of transportation, such as public transit. Consequently, we build upon the existing work to further examine impacts on urban transportation.

Due to the rich parking data from SFpark's pilot evaluation program, a few academic studies have already examined certain aspects of SFpark. A study by Millard-Ball, Weinberger \& Hampshire (2014) found that SFpark moved occupancy rates closer to the target range and reduced cruising. Other studies by Pierce \& Shoup, (2013a) and Millard-Ball, Weinberger \& Hampshire (2013) examined parking price elasticities based on SFpark. However, studies on parking still make up a small portion of the transportation literature and many gaps remain. For

\footnotetext{
${ }^{1}$ Block faces in Downtown, Fillmore, Fisherman's Wharf and South Embarcadero had metered parking after 6pm prior to SFpark. In the Fillmore parking management district, meter rates after 6pm started during rate adjustment period 9 or February 2013.

${ }^{2}$ The introduction of Sunday metered on-street parking took place in Mission, Marina, Union, Hayes Valley, Civic Center, Fillmore, and Richmond. This included pilot and control blocks, where demand responsive pricing was used in pilot blocks and traditional flat meter rates were used in control blocks. On-street parking was already metered in Downtown, Fisherman's Wharf and South Embarcadero.
} 
example, most of the literature on cruising for parking, a topic that has received more attention in this field, is theoretical. The few empirical studies on this topic mostly utilize survey data or videotaping, which are informative, but may lack generalizability across different populations. There is even less known about modal transportation choice, which only a handful of empirical studies have addressed explicitly (e.g., Gillen, 1977; Heshner \& King, 2001; Merriman, 1998; Millard-Ball, Weinberger \& Hampshire, 2014). Finally, as more smart-parking programs are implemented in growing urban centers, there is a shortage of rigorous empirical analysis that these programs will accomplish their goals. Though, early analyses of SFpark suggest SFpark has been successful thus far in achieving some of their target outcomes, particularly parking availability (e.g., Millard-Ball, Weinberger \& Hampshire, 2014; Pierce \& Shoup, 2013a; SFMTA, 2014), more empirical research is needed to discern other outcomes of interest for policymakers, including impacts on public transit and the effects of new meter installations.

\subsection{DATA AND EMPIRICAL APPROACH}

\subsection{SFMTA HOURLY DATA}

We use hourly SFMTA data, which includes information on hourly occupancy rates and meter rates for each block face, time band and rate adjustment period. We have data from April 2011 to July 2013 on both pilot and control block faces. The first rate adjustment period for block faces varies between July 21, 2011 (89.9\% of observations) and October 4, 2011 (1.3\% of observations). Since we are also interested in parking policies, we include information on block faces where new meters were installed as a result of SFpark. Prior to their installation, these block faces had either no parking limits or time-enforced limits. More information about these data are in Appendix A.

We also collect congestion data used during the SFpark evaluation. Roadway sensors were installed at 56 locations throughout the city in participating parking management districts, which included 46 access points, 62 repeaters, and 346 sensors (SFMTA, 2013). SFpark collected data on various metrics of congestion, including lane occupancy, volume and average speed. Data were collected every 15 minutes for 24 hours per day. Due to missing information about hourly data in the publicly available files, we aggregate data up to the daily level.

\subsection{MUNI TRANSIT BUS DATA}

We also obtain a rich data set of 14.8 million observations at the bus shift-stop level for the Muni bus system that includes detailed information such as the number of people who embark and disembark at each bus stop and time, distance between stops and maximum velocity. Given the level of detail in these data, they are only available during certain seasons of the year, so for this study, we focus on October to December for years 2009 to 2013. Nonetheless, the use of these data allows us to provide the first empirical estimates of the effects of parking management programs upon transit usage and quantify the modal shift at a micro level. 


\subsection{MERGING MUNI TRANSIT BUS DATA WITH SFMTA HOURLY DATA}

We generate a novel panel data set and merge Muni bus data with SFMTA hourly data. Muni bus data are aggregated to the census block level. SFpark data are at the block face level, which is different than the census block since parking occurs on the sides of streets. Also, in some cases one block face can span more than 1 census block (Figure 3-1), so we aggregate SFpark data to the census block level. Of the 2,715 block faces that include SFpark pilot and control blocks, 369 blocks cross one or more census blocks. We merge these data with information on bus stops within $500 \mathrm{ft}$ of the centroid of each census block level using a GIS map. We then merge these data with the Muni bus data. Since we only have Muni bus data for certain parts of the year, observations for both SFpark and bus data overlap for October to December 2011 and 2012, or rate adjustment periods 2, 3, 7 and 8. Although this limits the generalizability of our results, we still cover a large geographic area in the city and it should not produce any systematic bias in our results.

\subsection{EMPIRICAL APPROACH}

For our empirical strategy, we focus on using a difference-in-differences approach (DiD), a quasi-experimental method of program evaluation. A "before-after" approach to policy is undertaken using "treatment” groups which receive a specific intervention and "control” blocks. By observing these two groups before and after the intervention, it is possible to deduce the effect of the intervention by simply taking the difference of an outcome in the two groups before and after the intervention. In our case, the intervention is the SFpark program, groups are the pilot and control parking blocks, "treatment" is being designated an SFpark block, in this case the SFpark "pilot blocks", and the before and after time periods refer to the period immediately prior to and after SFpark.

As is typical in DiD settings, our regression frameworks include controls for characteristics that are time invariant and time-varying, ensuring that factors such as time trends of increases are accounted for. This ensures that the pilot and control blocks are allowed to differ along dimensions most relevant, and that the results obtained here focus on the effect of SFpark are valid given rather weak conditions. Results using DiD remain unbiased given that trends driving the outcomes of interest do not differ in their overall macro-economic response (e.g. different rates of traffic pattern changes) over time, which is called "common trend" assumption. While not testable per se, throughout the paper we indicate why this assumption is plausible for all our outcomes by looking at trends prior to SFpark for treatment and control groups. 


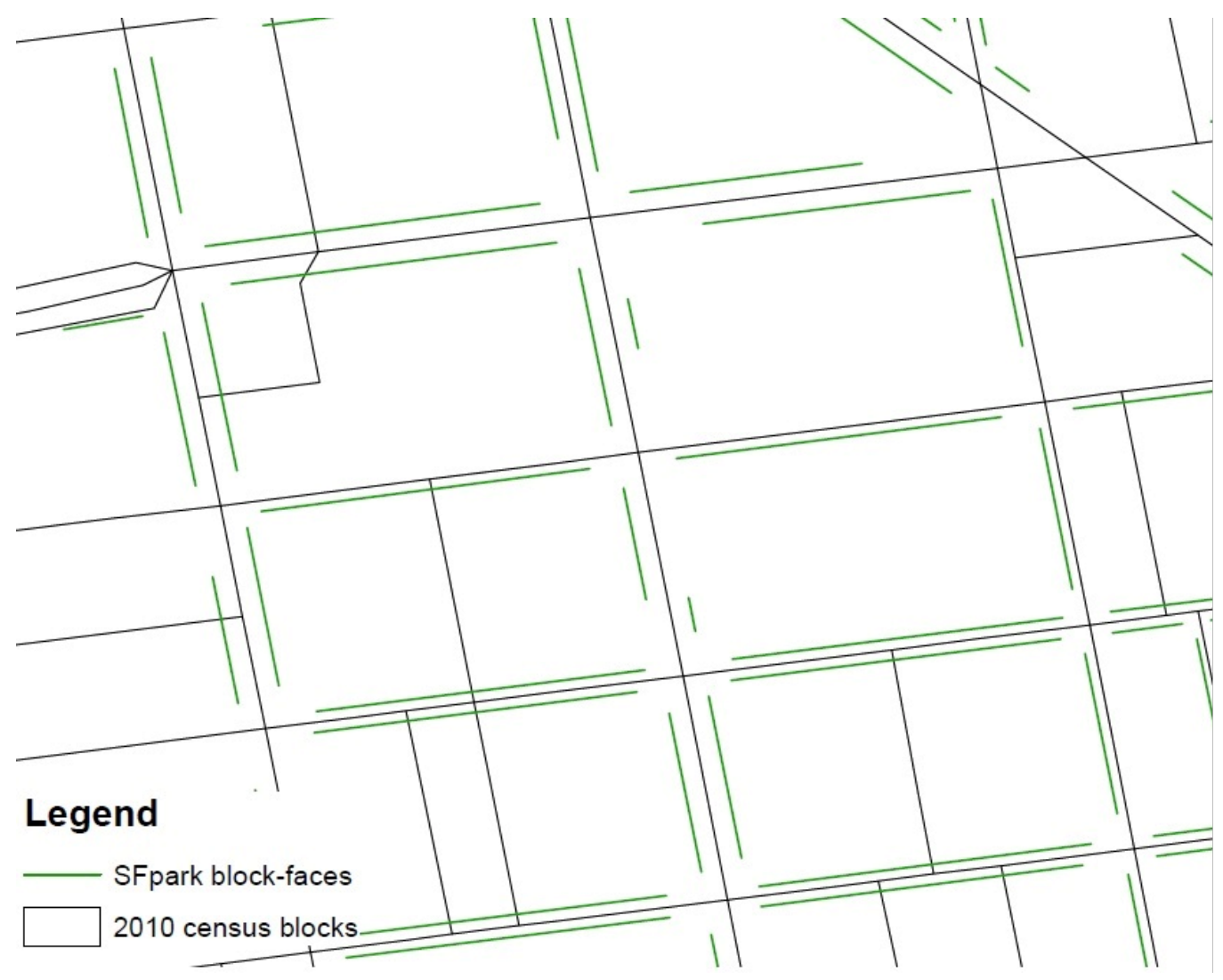

Figure 3-1. Example of parking block faces assigned by SFpark (green lines) and census blocks from the 2010 U.S. Census (black lines).

Note: In some cases, the SFpark block faces overlap more than 1 census block. Since we do not have block id numbers for all block faces but only for block faces with SFpark pilot and control groups, we aggregate data to the census block level. While some block-faces easily correspond to census blocks because these block-faces fall "completely inside" a census block, other block-faces are harder to characterize since they may span several census blocks, as demonstrated in the figure. Of the 2,715 block-faces that include pilot and control blocks as part of SFpark, 369 blocks cross one or more census blocks. We discuss how we merge these data with transit bus data further in the text (see 3.3). 


\subsection{IMPACT ON OCCUPANCY RATES}

\subsection{REGRESSION FRAMEWORK}

We first assess whether SFpark achieved its primary objective of meeting the target occupancy range for on-street parking. We use a DiD model to compare effects between the SFpark pilot and control groups before and after its implementation. We address this in Figure 41 by graphing average monthly occupancy and find that trends prior to the implementation of SFpark, which is represented by the vertical line in July 2011, are similar for both control and pilot block faces. This suggests a DID model will generate unbiased results. We explore the effect of SFpark on distance from the target occupancy range using the following specification:

$$
\begin{aligned}
& \text { dist }_{\text {bphdmy }}=\alpha_{0}+\alpha_{1} \text { post } * \text { pilot }_{d m y}+\alpha_{2} \text { post }_{d m y}+\alpha_{3}{\text { district } * y_{\text {ear }}+\alpha_{4} \text { time }_{\text {hdm }}+}_{\text {(4-1) }}+ \\
& \alpha_{5} \text { blockface }_{b}+\Gamma \boldsymbol{W}_{d m y}+\epsilon_{\text {bphdmy }}
\end{aligned}
$$

where dist is the distance from the target occupancy range of 60-80\% at SFpark block face $b$ in parking management district $p$ and at hour $h$, day $d$, month $m$, and year $y$. The independent variable of interest is post * pilot which is an interaction variable between post, a dummy variable equal to 1 if the rate adjustment period is $\geq 1$ and 0 otherwise, and pilot, a dummy variable equal to 1 if the block face was part of SFpark's pilot program and 0 otherwise. We account for annual trends across different parking management districts by interacting a parking management district fixed effect (FE) with a year-trend (district $*$ year). We also control for changes over time, such as seasonality, by including month, day-of-week and time band FEs in time. ${ }^{3}$ We account for time-invariant characteristics at the block face level by including block face FEs $\left(\right.$ blockface $\left._{b}\right)$. We also control for daily maximum temperature and precipitation in $\boldsymbol{W}$. We cluster standard errors at the block face level to account for spatial correlation within block faces.

However, one possible drawback of using equation (4-1) is that it masks the marginal effects from individual rate adjustment periods. As a result, we use a similar specification as in Millard-Ball, Weinberger \& Hampshire (2014) and observe the marginal effect of an additional rate adjustment period on distance to the target occupancy range.

$$
\begin{aligned}
& \text { dist }_{\text {bhpdmy }}=\beta_{0}+\beta_{1} \text { rate adjustment period } \\
& \text { blocky } \text { ace }_{b}+\Lambda \boldsymbol{W}_{d m y}+v_{\text {bphdmy }}
\end{aligned}
$$

Equation (4-1) is similar to equation (4-2), but the independent variable of interest is the number of rate adjustment periods between 0 and 10. In this model, all control blocks are assigned rate adjustment periods of 0 since they did not experience any rate adjustments throughout the study. We include the same control variables as in equation (4-1) and cluster standard errors at the block face level.

\footnotetext{
3 The day-of-week FE also accounts for differences in metered parking on Sundays, which was mostly free until January 6, 2013 when some parking management districts started charging for parking between 12pm and 6pm as part of SFpark. Also, on-street parking policies after 6pm did not change in most parking management districts, except in Fillmore where metered parking after 6pm started February 2013. Differences in the implementation of onstreet metered parking on Sundays or after 6pm should be accounted for the in district *year.
} 
The coefficients of interest in equations (4-1) and (4-2) are $\alpha_{1}$ and $\beta_{1}$ (resp.), where $\alpha_{1}$ represents the difference in distance to the target occupancy range between SFpark pilot and control groups after SFpark was implemented and $\beta_{1}$ represents the marginal effect of another rate adjustment period on the distance from the target occupancy. Since its implementation was pre-determined by bureaucratic decisions, we rely on the timing of SFpark being plausibly exogenous to factors that affect parking availability after conditioning on observables. We expect $\alpha_{1}$ and $\beta_{1}<0$ since demand-responsive parking should reduce the distance from the target occupancy range of 60-80\%, increasing parking availability and turnover. In addition to demandresponsive parking, SFpark also made on-street parking more convenient by allowing for the use of credit cards at meters and other mechanisms. Consequently, we do not observe the effect of a single part of SFpark, but as a whole.

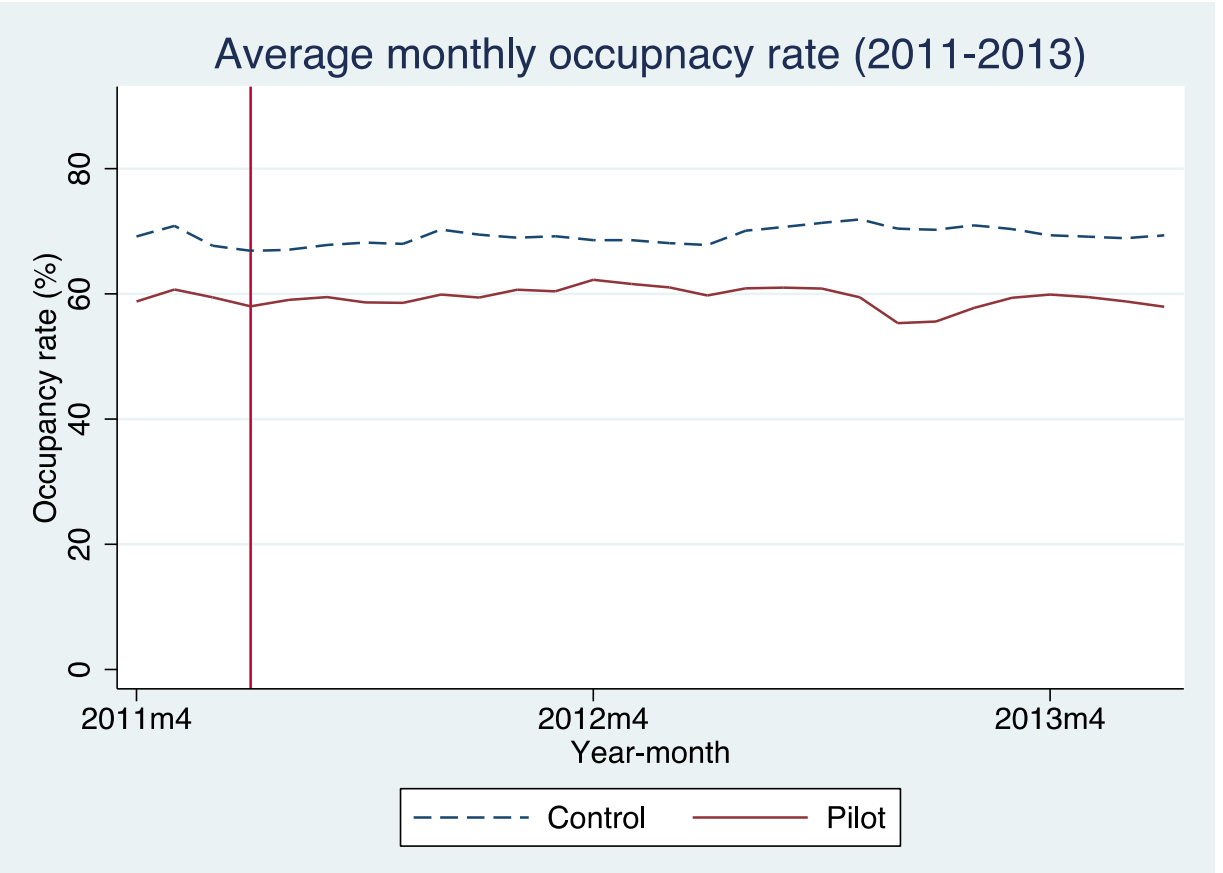

Figure 4-1: Graph of average monthly parking occupancy for pilot and control blocks before and after SFpark, which started in July 2011 (represented by the vertical line)

\subsection{RESULTS}

Results are in Table 2, where each column and panel represents a different regression. Panel A, column 1 shows results using equation (4-1), and we find a marginally significant decrease of 0.53 percentage points $(p<0.10)$ to the target occupancy range at SFpark pilot block faces after SFpark was implemented relative to the control group and prior to SFpark. Panel B, column 1 shows results for equation (4-2), and we find similar results to those in Millard-Ball, Weinberger \& Hampshire (2014), where an additional rate adjustment period is associated with a statistically significant 0.23 percentage point $(p<0.05)$ shift toward the optimal occupancy range. Both results suggest that SFpark reduces the distance to the target 
occupancy range, either increasing occupancy for blocks that are too empty or decreasing occupancy in blocks that are originally too full.

We then consider variation across block faces and over time. For example, there may be greater impacts on occupancy for block faces with newly installed meters, which accounts for $1.8 \%$ of SFpark block faces. Prior to installing meters, parking at these spots was unregulated or had time-restricted limits. The impacts of newly installed meters could matter to policymakers since anecdotally businesses are concerned with the effects of metered parking on sales. However, there is little empirical evidence of its effects (Hymel 2014). Consequently, observing the impacts of new meters on parking occupancy could be informative, since it captures some measure of foot traffic. In this case, we expect a greater effect on occupancy because pricing parking should increase turnover. We perform another regression using equation (4-1) and include an interaction term between post * pilot and a dummy variable equal to 1 if the block face had a new meter installed. To account for variation within and across days, we also include interaction terms with different time bands, where the reference category is after $6 \mathrm{pm}$, and with weekday, where the reference category is the weekend, and a separate weekday dummy variable. SFpark should provide the most relief to drivers during rush hour on weekdays. We perform a similar regression using equation (4-2), but interact dummy variables with rate adjustment period. The coefficients of interest are on the interaction terms.

Results are in column 2 of Table 2. In panel A, we find no significant difference in distance to the target occupancy range for blocks with newly installed meters. This could be due to the small number of blocks with new meters. However, we find distance decreases for all time bands relative to the reference category (after $6 \mathrm{pm}$ ) by approximately 2 percentage points. We also find a decrease in distance during weekdays compared to weekends of 1.4 percentage points. The latter two results are statistically significant, suggesting that on a whole, SFpark reduced distance to the target range between the morning and evening on weekdays. In panel B, column 2, the only significant coefficients are in the morning and weekdays, suggesting effects are more consistent during these times given an additional rate adjustment period. 
Table 4-2: Impacts of SFpark on distance from the target occupancy range of $60-80 \%$

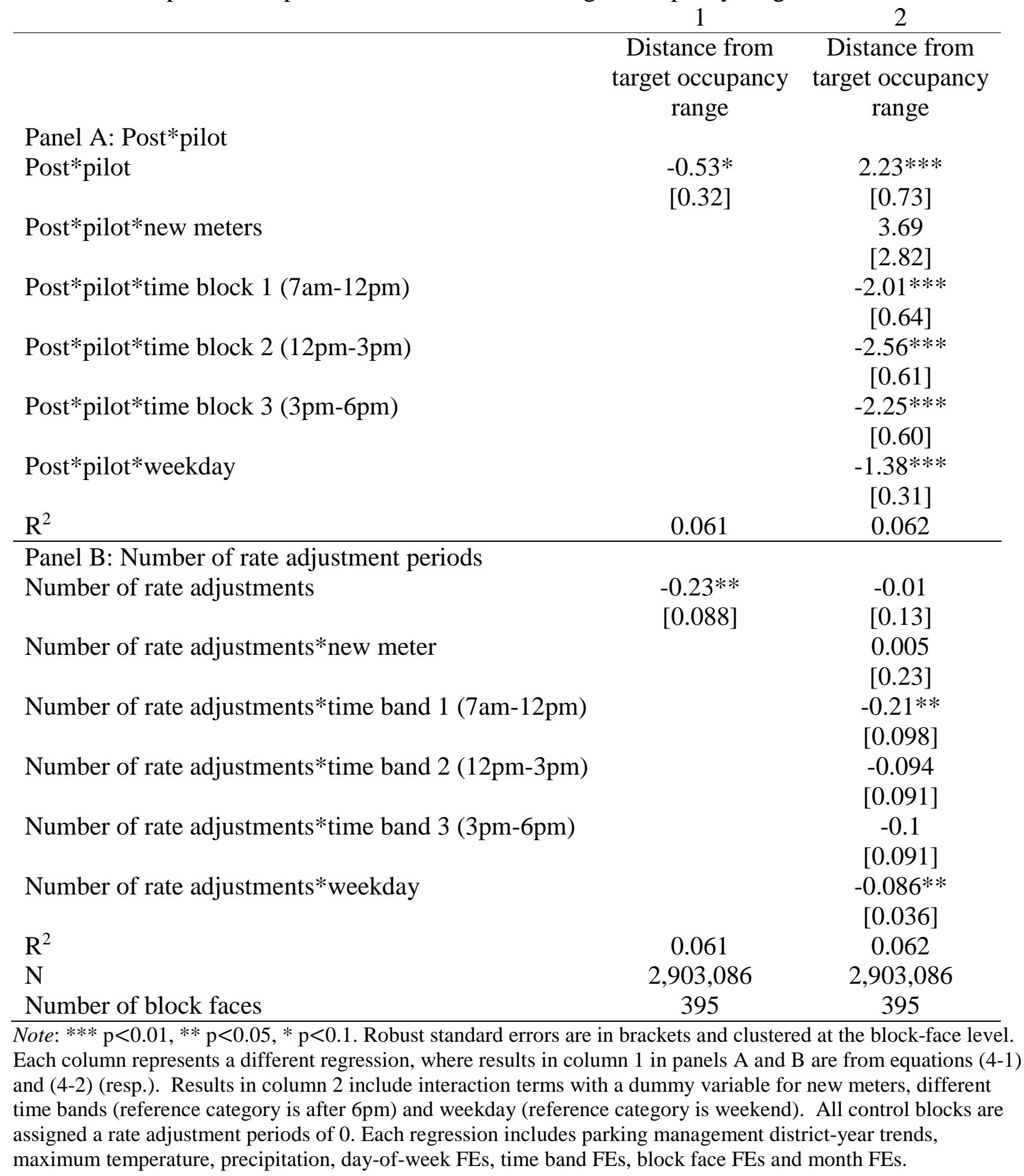




\subsection{TRANSIT USAGE}

An understudied topic in the transportation literature is how parking influences modal transportation choice, which has important implications for transportation policies. A travel mode share survey by SFMTA (2016) of Bay Area residents ${ }^{4}$ in 2015 found that 23\% of residents relied on public transit, while $47 \%$ used a private automobile. When asked what motivated them to drive, the greatest influences were speed and convenience, then distance between the destination and parking and parking price, where $50 \%$ of residents considered parking prices as being "free or cheap" as a strong motivator to drive. Of the respondents that reduced the number of cars in their household, $9 \%$ cited lack of parking as a major reason, while 4\% considered expensive parking costs as a factor. Another survey in 2005 of San Francisco Bay Area commuters reinforced this survey's findings, suggesting this relationship between parking management policies and mode choice has persisted over time. This survey found that if commuters were given a scenario where parking was free, only $5 \%$ of commuters would take the bus and 75\% would drive alone (SFMTA, 2014). However, if parking was not free, then $43 \%$ would take the bus and 37\% would drive alone. These survey results suggest SFpark could influence commuters' mode choice, though very few studies have examined this empirically using micro-level data or, specifically, demand responsive parking pricing programs.

\subsection{REGRESSION FRAMEWORK}

We investigate the impacts of SFpark across rate adjustment periods on Muni bus ridership. Since the intention of SFpark was to improve parking availability, it did not involve any reconfiguration of bus routes and schedules. As a result, we anticipate that any differences in ridership usage identified between SFpark and non-SFpark blocks are largely driven by SFpark itself. We again use a DiD framework, where control blocks are any blocks for which we have Muni bus data during October, November and December between 2009 and 2013 and that are not part of the SFpark pilot program in San Francisco. We consider the "common trend" assumption and plot average daily pre-SFpark ridership trends for weekdays only in Figure 5-1 and show they are similar in 2009 and 2010 between October and December. We use the following specification:

ridership $_{n c t}=\gamma_{0}+\gamma_{1}$ post $*$ pilot $+\gamma_{2}$ post $+\gamma_{3}$ neighborhood $*$ year r $_{n t}+$ time $_{\boldsymbol{t}}+$ census block ${ }_{c}+\rho \boldsymbol{W}_{t}+\omega_{\text {nct }}(5-1)$

where the dependent variable, ridership, is the total number of people who embark and disembark at bus stops within $500 \mathrm{ft}$ of the centroid of census block $c$ in neighborhood $n$ at the time band, date level $t$. Similar to equation (4-1), our independent variable of interest is on the interaction term, post $^{*}$ pilot, where $\gamma_{1}$ represents differences in ridership between pilot and control blocks after SFpark was implemented. We also control for weather, specifically maximum temperature and precipitation, neighborhood-year trends, day-of-week FEs, month FEs, and time-band FEs. Finally, we include census block FEs and standard errors are clustered at the census block level.

\footnotetext{
${ }^{4}$ This includes San Francisco and 8 surrounding counties
} 
In this case, $\gamma_{1}$ could be positive or negative. For example, if parking supply constraints were the main reason individuals were taking the bus instead of driving, then we expect $\gamma_{1}<0$ due to improved parking availability or convenience from SFpark. However, we could also expect $\gamma_{1}>0$ if meter rates in high-demand areas increased, for example, and exceeded some drivers' willingness to pay, prompting them to substitute the car with the bus.

Although in using these models we cannot clearly conclude that any changes in transit ridership correspond to changes in auto usage since we do not have information on explicit mode choice, there are unlikely other mechanisms through which SFpark could affect ridership due to the exogenous nature of the timing and geography of SFpark. However, we are cautious to make a causal argument and these reduced-form results are better viewed as a baseline for further investigation of this relationship, rather than as comprehensive measures of the effects of parking upon mode choice.

\subsection{RESULTS}

Results are in Table 5-1 where each column and panel represents a different regression. The average number of people embarking and disembarking at bus stops within $500 \mathrm{ft}$ of the census block at SFpark pilot blocks is 180 people between 2009 and 2013 for October to December. In panel A, column 1 , we find $\gamma_{1}$ is positive, significant effect suggesting 16 more people embarked and disembarked from the bus on pilot blocks after SFpark was implemented compared to control blocks prior to SFpark $(p<0.01)$, which represents $9 \%$ of average ridership. We also interact post*pilot with a dummy variable for blocks with new meters in column 2 and find no significant effect. However, we find a statistically significant increase on transit ridership during morning and afternoon rush hour after interacting time bands with post*pilot in column $3(p<0.01)$ relative to ridership after $6 \mathrm{pm}$. This suggests possible substitution away from non-transit travel to transit travel on pilot blocks after SFpark during rush hour.

We explore possible mechanisms for changes in transit ridership at pilot blocks after SFpark. By treating pilot blocks that experience a price change the same as blocks that do not, we could mask possible heterogeneity among commuters who factor parking price into their mode choice. We use equation (5-1) and include a continuous variable for average changes in metered rates for a given census block, time band and day type from the previous adjustment period. ${ }^{5}$ We also include an interaction term between changes in rates and the post*pilot interaction effect. The coefficient of interest is on the interaction term, which represents the effect of a \$1 change in metered rates on SFpark blocks after the program was implemented. It could be positive or negative since price changes could have two distinct and opposing effects on transit usage, where price increases could increase parking availability, but also raise the relative price of parking. Rate changes for SFpark pilot blocks after SFpark was implemented vary between $\$-0.57$ and $\$ 0.38$, where the average absolute value of rate changes is $\$ 0.10$.

Results are in column 4 of Table 5-1. After including the other interaction effects, we find a positive effect on the interaction term between post*pilot and rate changes. This suggests that a \$1 increase in metered rates on pilot blocks after SFpark was implemented is associated

\footnotetext{
${ }^{5}$ Rate changes occur at the block-face level and one census block can have multiple block faces, so we aggregate rate changes from the block face to the census block level by taking the average rate change across block faces. Given the close proximity of block faces at a particular census block, it is unlikely that we are masking important heterogeneity in rate changes by averaging across increases and decreases in meter rates from the previous period.
} 
with 57 more people using the Muni transit bus relative to control blocks prior to SFpark. Since the average absolute value of rate changes is $\$ 0.10$, on average 6 more people take the bus at SFpark pilot blocks after the program was implemented, which represents $3 \%$ of average ridership.

\subsection{OTHER TESTS AND ROBUSTNESS CHECKS}

To test the strength of our results, we observe whether our results are robust to different specifications and subsamples. First, we use equation (5-1) and examine impacts on a subsample by focusing on pilot and control blocks included in the SFpark evaluation only instead of using all blocks with bus stops. There may be concerns that control and pilot blocks systematically differ since we include blocks that were not part of SFpark's evaluation, which could make results less generalizable. Results including all interaction terms are in column 5 of Table 5-1 using the DiD framework, and we find the same pattern with increases during rush hour and a positive significant effect from rate changes similar in size to column 4.

We also consider impacts using an equation similar to (5-1), but the independent variable of interest is the number of rate adjustment periods instead of the interaction term post* ${ }^{*}$ ilot. Results are in Table 5-2, where column 1 shows results using the larger sample including all blocks with bus stops in San Francisco, and we find a similar pattern as in Table 5-1, with a positive significant effect from rate changes. This suggests that given an additional rate adjustment period, a $\$ 1$ increase in metered rates is associated with an increase in transit bus ridership of 12 people, or of 1 person for a $\$ 0.10$ increase in metered rates. In column 2, we show effects for the subsample including blocks in SFpark's evaluation only and find slightly different results, where the effect of morning rush hour is insignificant while the difference during the afternoon period is negative and significant. Also, we find a positive effect on the interaction term for rate changes, but the coefficient is not significant. While the latter results are more puzzling, it could be due to the sensitivity of ridership to different rate adjustment periods.

In keeping with our data limitations, our analysis demonstrates an aggregate pattern of substitution between transit and non-transit travel, which we reasonably assume is auto usage, during rush hour and in response to meter rate increases. The positive relationship between parking price and ridership suggests changes in metered rates have a modest effect on mode choice and in the direction commuter surveys have shown. In which case, by treating blocks with no rate change the same as blocks that experience a rate change, the effect of SFpark on transit ridership may be misleading. 
Table 5-1: Impacts of SFpark on Muni bus transit ridership using equation (5-1)

\begin{tabular}{|c|c|c|c|c|c|}
\hline & $\begin{array}{c}1 \\
\text { Embark } \\
\text { and } \\
\text { disembark }\end{array}$ & $\begin{array}{c}2 \\
\text { Embark } \\
\text { and } \\
\text { disembark }\end{array}$ & $\begin{array}{c}3 \\
\text { Embark } \\
\text { and } \\
\text { disembark }\end{array}$ & $\begin{array}{c}4 \\
\text { Embark } \\
\text { and } \\
\text { disembark }\end{array}$ & $\begin{array}{c}5 \\
\text { Embark } \\
\text { and } \\
\text { disembark }\end{array}$ \\
\hline Post*pilot & $\begin{array}{c}15.8^{* * * *} \\
{[4.38]}\end{array}$ & $\begin{array}{c}15.1^{* * *} \\
{[4.31]}\end{array}$ & $\begin{array}{c}-14.6^{* * *} \\
{[3.94]}\end{array}$ & $\begin{array}{c}-15.4^{* * * *} \\
{[3.88]}\end{array}$ & $\begin{array}{c}30.5^{* * *} \\
{[4.27]}\end{array}$ \\
\hline Post*pilot*new meters & & $\begin{array}{c}14 \\
{[18.0]}\end{array}$ & & $\begin{array}{c}8.97 \\
{[17.4]}\end{array}$ & $\begin{array}{c}4.24 \\
{[16.7]}\end{array}$ \\
\hline Post*pilot*time block 1 & (7am-12pm) & & $\begin{array}{c}97.0^{* * *} \\
{[12.1]}\end{array}$ & $\begin{array}{c}98.4^{* * * *} \\
{[12.3]}\end{array}$ & $\begin{array}{c}38.8^{* * *} \\
{[6.57]}\end{array}$ \\
\hline Post*pilot*time block 2 & $(12 \mathrm{pm}-3 \mathrm{pm})$ & & $\begin{array}{l}-3.62 \\
{[3.19]}\end{array}$ & $\begin{array}{l}-5.31 * \\
{[3.14]}\end{array}$ & $\begin{array}{c}-14.7 * * * \\
{[2.45]}\end{array}$ \\
\hline Post*pilot*time block 3 & $3(3 p m-6 p m)$ & & $\begin{array}{c}44.4 * * * \\
{[5.30]}\end{array}$ & $\begin{array}{c}43.3^{* * * *} \\
{[5.19]}\end{array}$ & $\begin{array}{c}11.5^{* * * *} \\
{[3.34]}\end{array}$ \\
\hline Post*pilot*rate change & & & & $\begin{array}{c}57.3^{* * *} \\
{[13.9]}\end{array}$ & $\begin{array}{c}55.1 * * * \\
{[14.1]}\end{array}$ \\
\hline $\mathrm{R}^{2}$ & 0.087 & 0.087 & 0.092 & 0.091 & 0.198 \\
\hline $\begin{array}{l}\mathrm{N} \\
\text { Numbe }\end{array}$ & $5,646,158$ & $5,646,158$ & $5,646,158$ & $5,646,158$ & 323,984 \\
\hline $\begin{array}{l}\text { Number c } \\
\text { blocks }\end{array}$ & 5,364 & 5,364 & 5,364 & 5,364 & 281 \\
\hline
\end{tabular}

Note: ${ }^{* * *} \mathrm{p}<0.01,{ }^{* *} \mathrm{p}<0.05,{ }^{*} \mathrm{p}<0.1$. Robust standard errors are clustered at the census block. Each column represents a separate regression. The dependent variables is the total number of people who embark and disembark at bus stops within $500 \mathrm{ft}$ of the centroid of a census block. These data only include rate adjustment periods 2, 3, 7 and 8; control blocks are assigned a rate adjustment period of 0 . See note for Table 4-1. The Muni bus transit data are at the time band-census block level. Each regression accounts for neighborhood-year trends, precipitation, maximum temperature, day-of-week FEs, month FEs and time-block FEs. 
Table 5-2: Impacts of SFpark on Muni bus transit ridership using a different specification

\begin{tabular}{|c|c|c|}
\hline & $\begin{array}{c}1 \\
\text { Embark } \\
\text { and } \\
\text { disembark }\end{array}$ & $\begin{array}{c}2 \\
\text { Embark } \\
\text { and } \\
\text { disembark }\end{array}$ \\
\hline Number of rate adjustments & $\begin{array}{c}-0.67 \\
{[1.16]}\end{array}$ & $\begin{array}{c}4.14^{* * *} \\
{[1.23]}\end{array}$ \\
\hline Number of rate adjustments*new meters & $\begin{array}{c}-1.62 \\
{[1.34]}\end{array}$ & $\begin{array}{l}-1.23 \\
{[1.11]}\end{array}$ \\
\hline $\begin{array}{l}\text { Number of rate adjustments*time block } 1 \text { (7am- } \\
12 \mathrm{pm})\end{array}$ & $\begin{array}{c}12.3 * * * \\
{[178]}\end{array}$ & -0.015 \\
\hline $\begin{array}{l}\text { Number of rate adjustments*time block } 2 \\
(12 \mathrm{pm}-3 \mathrm{pm})\end{array}$ & $\begin{array}{c}-3.85 * * * \\
{[1.29]}\end{array}$ & $\begin{array}{c}-5.67 * * * \\
{[1.29]}\end{array}$ \\
\hline $\begin{array}{l}\text { Number of rate adjustments*time block } 3 \text { (3pm- } \\
6 \mathrm{pm})\end{array}$ & $\begin{array}{c}3.78^{* * * *} \\
{[1.26]}\end{array}$ & $\begin{array}{c}-2.81^{* *} \\
{[1.23]}\end{array}$ \\
\hline Number of rate adjustments*rate change & $\begin{array}{c}11.8^{* * *} \\
{[3.88]}\end{array}$ & $\begin{array}{c}4.27 \\
{[3.35]}\end{array}$ \\
\hline $\mathrm{R}^{2}$ & 0.086 & 0.189 \\
\hline $\mathrm{N}$ & $5,646,158$ & 323,984 \\
\hline $\begin{array}{l}\text { Number of census blocks } \\
\left.\text { ote: }{ }^{* * *} \mathrm{p}<0.01 \text {, }^{* *} \mathrm{p}<0.05\right)^{*} \mathrm{p}<0.1 \text {. See table notes for }\end{array}$ & $\begin{array}{l}5,364 \\
5-1 . \text { The inc }\end{array}$ & $\begin{array}{c}281 \\
\text { pendent varia }\end{array}$ \\
\hline
\end{tabular}

\subsection{CONGESTION}

\subsection{DAILY LANE OCCUPANCY, VEHICLE COUNT AND SPEED}

We also consider the effects of SFpark on many key measures of congestion. The relationship between parking availability and congestion has many facets, though most previous work focuses on cruising (e.g., Millard-Ball, Weinberger \& Hampshire, 2014). We explore this further and use similar specifications as equations (4-1) and (4-2), but different outcomes of interest. Also, we aggregate data to the census block level instead of the block face level. We do not account for heterogeneity with respect to meter rate changes since aggregating positive and negative rate changes across time bands to the daily level could be misleading (e.g., meter rates could vary greatly between the morning rush hour versus the early afternoon). However, given the relationship between rate changes and congestion is less clear, we do not consider this a major concern.

We expect reduced congestion after SFpark was implemented. Results are in Table 6-1 where each column and panel represents a different regression. Results using the DiD model are 
in panel A while the marginal impact of rate adjustment periods is in panel B. We focus on three outcomes of interest: percentage of time a car was detected above the sensors or lane occupancy (columns 1 and 2), average vehicle count (columns 3 and 4), and average speed (columns 5 and 6). In columns 1,3 , and 5, we do not include any interaction terms, and in columns 2 , 4, and 6 , we include interaction terms with dummy variables for blocks with newly installed meters and weekdays.

In panel A, column 1, we find that relative to the control group and prior to SFpark, there is a statistically significant reduction in lane occupancy by 5 percentage points $(p<0.01)$ (average daily lane occupancy in this sample is $18 \%$ ). However, in column 2 , we find a statistically significant increase in congestion at blocks with new meters. In panel B, columns 1 and 2, we find no significant effect from an additional rate adjustment period, but we find a slight increase in lane occupancy of 0.19 percentage points $(\mathrm{p}<0.05)$ at blocks with new meters. In columns 3 and 4, we observe impacts on average vehicle count and find no significant effects in panels A or $\mathrm{B}$, except a positive, significant effect on the interaction term with weekday in panel A (average vehicle count is 61). Finally, in columns 5 and 6, panel A, we find a significant decrease in average speed at blocks with new meters, but an increase in speed on weekdays, though the size of these effects are $<1 \%$ of the average speed of $23 \mathrm{mph}$. In panel $\mathrm{B}$, we find a small increase in average speed given an additional rate adjustment period, but a decrease at blocks with new meters.

Since congestion is a bigger concern on weekdays compared to the weekends due to the higher volume of commuters, we consider the total impact of SFpark on weekdays only. We add coefficients on the main term, either pilot * post or rate adjustment period, and the interaction term with weekday and adjust standard errors. This represents the effect of SFpark on weekdays on blocks where no new meters were installed, which is the majority of blocks. Results are in the first two rows of panel $\mathrm{C}$, and we find a negative effect on lane occupancy in column 2 using the DiD model, representing 20\% of average lane occupancy, on weekdays and a positive effect on average speed in column 6 , representing $3 \%$ of average speed. Both results are statistically significant. In row 2 of panel C, we find a positive, significant effect on average speed given an additional rate adjustment period. Next, we observe impacts of SFpark on weekdays at new blocks by adding coefficients on the main terms and both interaction terms. None of the effects is significant, suggesting that the increase in congestion at blocks with new meters occurs on the weekends, making the positive coefficient on new meters less of a concern.

These results suggest that SFpark led to reductions in congestion on weekdays, though the size of its impact varies by the outcome of interest, where SFpark had large impacts on lane occupancy, but a small effect on average speed. This small increase in traffic speed was also found in SFMTA's pilot evaluation (2014). There are some limitations to these data, however. First, by aggregating congestion measures from hourly to the daily level, we may be masking rich temporal heterogeneity that could be exploited to generate more precise results, which may explain the insignificant results in columns 3 and 4. Also, by aggregating data to the daily level, we are unable to account for meter rate changes which vary within days, though it is less clear how changes in meter rates affect congestion. Next steps could be to consider other measures of congestion at a finer temporal resolution, such as time between bus stops using the Muni bus data. 
Table 6-1: Impacts of SFpark on different average daily measures of congestion.

\begin{tabular}{|c|c|c|c|c|c|c|}
\hline & 1 & 2 & 3 & 4 & 5 & 6 \\
\hline & $\begin{array}{l}\text { Lane } \\
\text { occup }\end{array}$ & $\begin{array}{l}\text { Lane } \\
\text { occup }\end{array}$ & $\begin{array}{l}\text { Vehicle } \\
\text { count }\end{array}$ & $\begin{array}{l}\text { Vehicle } \\
\text { count }\end{array}$ & Speed & Speed \\
\hline \multicolumn{7}{|l|}{ Panel A: Post*pilot } \\
\hline \multirow[t]{2}{*}{ Post*pilot } & - & - & -4.51 & 0.73 & -0.67 & 0.43 \\
\hline & $\begin{array}{c}5.15^{* * *} \\
{[1.78]}\end{array}$ & $\begin{array}{l}3.95^{* *} \\
{[1.81]}\end{array}$ & [2.85] & [2.69] & [0.58] & [0.31] \\
\hline Post*pilot*new meters & & $\begin{array}{l}1.10^{* *} \\
{[0.45]}\end{array}$ & & $\begin{array}{c}-0.31 \\
{[0.60]}\end{array}$ & & $\begin{array}{l}-0.21^{* *} \\
{[0.099]}\end{array}$ \\
\hline Post*pilot*weekday & & $\begin{array}{c}0.33 \\
{[0.21]}\end{array}$ & & $\begin{array}{l}0.88^{* *} \\
{[0.39]}\end{array}$ & & $\begin{array}{l}0.25^{* * *} \\
{[0.070]}\end{array}$ \\
\hline $\mathrm{R}^{2}$ & 0.067 & 0.068 & 0.054 & 0.054 & 0.024 & 0.023 \\
\hline \multicolumn{7}{|c|}{ Panel B: Rate adjustment periods } \\
\hline Number of rate adjustments & $\begin{array}{l}-0.055 \\
{[0.090]}\end{array}$ & $\begin{array}{l}-0.089 \\
{[0.086]}\end{array}$ & $\begin{array}{l}0.032 \\
{[0.27]}\end{array}$ & $\begin{array}{l}0.024 \\
{[0.28]}\end{array}$ & $\begin{array}{l}0.064^{* *} \\
{[0.025]}\end{array}$ & $\begin{array}{c}0.069 * * * \\
{[0.025]}\end{array}$ \\
\hline $\begin{array}{l}\text { Number of rate } \\
\text { adiustments*new meters }\end{array}$ & & $\begin{array}{l}0.19 * * \\
{[0.094]}\end{array}$ & & $\begin{array}{c}0.2 \\
{[0.13]}\end{array}$ & & $\begin{array}{c}-0.053^{* *} \\
{[0.026]}\end{array}$ \\
\hline $\begin{array}{l}\text { Number of rate } \\
\text { adjustments*weekday }\end{array}$ & & $\begin{array}{c}0.025 \\
{[0.031]}\end{array}$ & & $\begin{array}{c}-0.04 \\
{[0.057]}\end{array}$ & & $\begin{array}{c}0.0069 \\
{[0.0098]}\end{array}$ \\
\hline $\mathrm{R}^{2}$ & 0.055 & 0.056 & 0.054 & 0.054 & 0.023 & 0.023 \\
\hline \multicolumn{7}{|c|}{ Panel C: Total effect on weekdays } \\
\hline & & $\begin{array}{c}- \\
3.62 * *\end{array}$ & & 1.61 & & $0.69 * *$ \\
\hline & & -0.064 & & -0.016 & & $0.076^{* * *}$ \\
\hline & & -2.52 & & 1.3 & & 0.47 \\
\hline & & 0.13 & & 0.18 & & 0.023 \\
\hline $\mathrm{N}$ & 59,340 & 59,340 & 59,340 & 59,340 & 59,340 & 59,340 \\
\hline Number of census blocks & 109 & 109 & 109 & 109 & 109 & 109 \\
\hline
\end{tabular}




\subsection{CONCLUSION}

Our results suggest that SFpark achieved its goal of increasing parking availability, agreeing with previous literature. We find that after SFpark, distance to the target occupancy range of $60-80 \%$ decreased, with greater impacts during peak periods on weekdays. However, we find no significant effects on occupancy from the installation of new parking meters, making the impacts of introducing metered parking less clear. Second, we find SFpark is associated with reductions in congestion on weekdays, the magnitude of which varies depending on the congestion measure.

Finally, we make a novel contribution to the literature by addressing the effect of SFpark on transit usage, and findings from our baseline specification show a small reduction in ridership at pilot blocks after SFpark was implemented. However, a core component of SFpark is allowing metered rates to fluctuate after a few weeks in response to occupancy rates. Given these unique changes in metered rates over time, we explore possible heterogeneous effects on transit usage across different blocks that experience an increase or decrease in rates. We find a positive relationship between rate changes and bus ridership, where a modest increase (decrease) in meter rates is associated with higher (lower) ridership. This implies that parking price is an important motivator in commuters' mode choice, thus supporting prior findings from commuter surveys. In keeping with our data limitations, our analysis speaks to an aggregate pattern of substitution between transit and non-transit travel. To our knowledge, this is the first study to observe this relationship using micro-level transit and parking data.

The fact that we find modest effects on transit usage and congestion is unsurprising since the main intent of SFpark was to improve parking availability. These results have important implications for transportation policy in the long run as these programs expand globally. Additionally, our results showing a positive relationship between rate changes and mode choice could be informative for transportation agencies and cities interested in raising flat meter rates or using a demand-responsive pricing programs. The fact that parking price could influence the choice between transit and other alternative forms of transportation reinforces the importance of parking policies on overall transportation in urban areas. 


\subsection{REFERENCES}

Anderson, M. L. (2014). Subways, strikes, and slowdowns: The impacts of public transit on traffic congestion. The American Economic Review, 104 (9), 2763-2796.

Asian Development Bank (2011) Parking policy in Asian cities.

Barter, P.A. (2010) Off-street parking policy without parking requirements: A need for marking fostering and regulation, Transport Review, 30, 5, 571-588.

Duranton, G. \& Turner, M. A. (2011). The fundamental law of road congestion: Evidence from U.S. cities. The American Economic Review, 101 (6), 2616-2652.

Fadeyev, D. (2017) Method for evaluating economic efficiency of parking management tools. Transportation Research Procedia, 20, 193-199.

Gillen, D. (1977). Estimation and specification of the effects of parking costs on urban transport mode choice. Journal of Urban Economics, 4, 186-199.

Heshner, D.A. \& King, J. (2001). Parking demand and responsiveness to supply, pricing and location in the Sydney central business district. Transportation Research Part A, 35, 177-196.

Hymel, K. (2014) Do parking fees affect retail sales? Evidence from Starbucks. Economics of Transportation, 3, 221-233.

Inci, E. (2015) A review of the economics of parking. Economics of Transportation, 4, 50-63.

Kodransky, M. and Hermann, G. (2011) Europe’s Parking U-Turn: From Accommodation and Regulation, The Institute for Transportation \& Development Policy.

Marsden, G. (2006). The evidence base for parking policies- A review. Transport Policy, 13, 447-457.

Merriman, D. (1998). How many parking spaces does it take to create one additional transit passenger? Regional Science and Urban Economics, 28, 565-584.

Millard-Ball, A., Weinberger, R. \& Hampshire, R. (2013). Comment on Pierce and Shoup: Evaluating the impacts of performance-based parking. Journal of the American Planning Association, 79, 330-335.

Millard-Ball, A., Weinberger, R. \& Hampshire, R. (2014). Is the curb $80 \%$ full or $20 \%$ empty? assessing the impacts of San Francisco's parking pricing experiment. Transportation Research Part A, 63, 76-92. 
Mingardo, G., van Wee, B., and Rye, T. (2015) Urban parking policy in Europe: A conceptualization of past and possible future trends. Transportation Research Part A, 74, 268281.

Pierce, G. \& Shoup, D. (2013a). Getting the prices right. Journal of the American Planning Association, 79, 67-81.

Pierce, G. \& Shoup, D. (2013b). Response to Millard-ball et al.: Parking prices and parking occupancy in San Francisco. Journal of the American Planning Association, 70, 336-339.

San Francisco Municipal Authority (SFMTA) (2013). Parking sensor data guide.

SFMTA (2014). SFpark pilot project evaluation.

SFMTA (2016). Travel decisions survey 2015 summary report.

Shoup (2011). The high cost of free parking. APA Planners Press.

Wang, R. and Yuan, Q. (2013) Parking practices and policies under rapid motorization: The case of China, Transport policy, 30, 109-116. 



\section{APPENDIX A}

\section{MORE INFORMATION ON SFPARK DATA}

Data were obtained from SFpark’s "Parking Sensor Data Guide” (found here: http://sfpark.org/resources/parking-sensor-data-guide/) and from e-mail exchanges with Prof. Millard-Ball. The original data set had 7,902,290 observations but a significant number were dropped to ensure that data met specific requirements. For example, we dropped 4,850,187 observations when meters were not operating, since the greatest effects will occur during metered times. We also dropped 54,072 observations in the parking management district of West Portal, which only included control blocks, since these observations were considered unreliable (p. 16). Next, we dropped 11,304 observations in the California and Steiner Lot, which included only pilot blocks, since we were most interested in on-street parking. We then dropped 37,541 observations for blocks at two streets, Howard St. 0 and Spear St. 400, since these streets had different meter rates for the same date and time of day. We dropped 1 observation which did not list if it was a control or pilot block and dropped 27,709 observations between December 10-17, 2012 on the advice of Prof. Millard-Ball. For the balanced panel, we only kept blocks that had continuous data from July 21, 2011. All control blocks are in the parking management districts of Inner Richmond and Union. All pilot blocks are in Civic Center, Downtown, Fillmore, Fisherman's Wharf, Marina, Mission, and South Embarcadero.

We identified blocks with newly installed meters that were part of the SFpark pilot group using the following information. As part of SFpark, "SFMTA introduced new meters in several areas inside and outside of SFpark pilot and control areas in 2011. These newly installed meters resulted in a dramatic improvement to parking availability. Prior to installing meters, these blocks were too full $90 \%$ of the time. After the installation of meters, this figure dropped to just $15 \%$ of the time" (SFMTA, p. 70). Based on archived SFMTA press releases in 2010, some of the pilot blocks correspond to the proposed installation of approximately 1300 meters (SFMTA 2014). We believe these blocks are part of the newly installed meters proposed by SFMTA that became part of SFpark for a couple reasons. In these archives, SFpark is not explicitly measured as the reason for installing these new meters, though a big motivation for installing new meters was because SFMTA was introducing "next-generation smart parking meters that accept credit cards, coins and the SFMTA parking card to make payment as convenient as possible," which essentially describes the objectives of SFpark. Any blocks with new meters that do not correspond to pilot blocks in SFpark were not considered. We then find if these proposed blocks correspond to pilot blocks using the SFMTA hourly data. Based on this method, out of 2715 blocks part of the SFpark pilot group, we found 50 blocks where meters were newly installed. 
Transportation Research and Education Center

Portland State University

1900 S.W. Fourth Ave., Suite 175

Portland, OR 97201 